\title{
The Effect of Job Satisfaction on Organizational Commitment of Healthcare Personnel
}

\author{
Serap Durukan Köse ${ }^{1}$, Tuncay Köse ${ }^{2}$ \\ ${ }^{I}$ (Assistant Professor, PhD,, Department of Health Management, Muğla Sitkı Koçman University, Turkey) \\ ${ }_{2}^{2}$ (Assistant Professor, PhD, , Department of Health Management, Muğla Sttkı Koçman University, Turkey)
}

\begin{abstract}
The purpose of this study is to assess the effect of the job satisfaction of health care personnel on organizational commitment's components. The data of the research were collected by way of a survey that was conducted on 501 health care workers who work in a public university hospital in Turkey. Structural equation modeling (path analysis) was conducted to test the hypotheses. From the results of the analyses, there was no statistically significant influence of intrinsic satisfaction on organizational commitment was found. Only extrintic satisfaction was determined significantly negative effect on continuance commitment and positive effect on normative commitment. In other words, an increase in the level of extrinsic satisfaction causes a decrease in continuance commitment and an increase in normative commitment.
\end{abstract}

Keywords: Job satisfaction, Organizational commitment, Healthcare personnel

\section{Introduction}

In the healthcare industry, particularly in the excessive division of labor and high level of specialization at hospitals, the inability to predict demands and uncertainties can lead to structural complexities. Thus, healthcare personnel at hospitals must use available resources in the most effective way in order to keep up with the latest technological advancements, maintain their existence, and more importantly, have a sound position in the industry. Although technological superiority provides certain advantages, the quality of the services rendered by the healthcare personnel plays an important role in achieving the objectives and goals of the organization. In this regard, the job satisfaction of such personnel is crucial since it not only affects the individual in question, but also the patients and the healthcare industry as a whole. It should not be overlooked that level of commitment of healthcare personnel to institution can be increased as the level of job satisfaction is increased.Organizational commitment, seen as a natural result of job satisfaction, has some meanings such as self-sacrifice in favor of the institution, devoting oneself to organizational goals, and participation in organizational benefit.

The main aim of this study is to examine the effect of job satisfaction level of healthcare personnel(doctor, nurse, other medical and administrative staff) working in a public university hospital on their organizational commitment level. It is believed that research findings and results will contribute to the field of human resources management in health institutions.

\section{Job Satisfaction}

\section{Job Satisfaction and Organizational Commitment}

Job satisfaction attracts attention of both those who work in organizations and research on the subject (Lu, While \& Barriball, 2005).Job satisfaction is, in a general sense, considered as the positive impact that the worker's experiences in the job environment have on him/her and the positive behaviours resulting from these experiences (Currivan, 1999; Weiss, 2002). The traditional model of job satisfaction focuses on one's all feeling about his/her own profession. However, the thing what makes the job satisfactory or unsatisfactory does not only depend on the quality of the job, but also the expectations of the individuals about their job (Lu, While \& Barriball, 2005). Participation in the decision-making process, job autonomy, integration, job diversity, satisfaction with pay, availability of incentive program, training, perceptions of equitable treatment, and quality of supervision, training, and formalization have been to lead to higher levels of job satisfaction (Lambert, Hogan \& Griffin, 2007).Herzberg formulated the two-factor theory of job satisfaction, one refers to "hygiene" factors that are extrinsic to the job (company policy and administration, supervision, relationship with supervisor, work conditions, salary, relationship with peers, personal life, relationship with subordinates, status, security) and the other one is known as "motivators" that are intrinsic to the job (growth, advancement, responsibility, work itself, recognition, achievement) (Güleryüz et al., 2008). 
Organizational commitment is the degree to which an employee feels loyalty to a particular organization (Currivan, 1999). Thus, organizational commitment acts as a psychological link to an organization which influences individuals act in ways that are consistent with the organization's interests (Yang \& Chang, 2008).Meyer and Allen, who focused on organizational commitment as a psychological state that reflects the relationship between an individual and an organization, argued that this state is determinative on the relations between the worker and the organization, and the decision of the former to remain in the latter (Larson \& Luthans, 2006; Shahnawaz \& Jafri, 2009). The commitment of employees is an indication of clinging more tightly to organizational objects, identification, integration with the organization, acceptance of organizational goals and values, and extraordinary effort for organizational benefit (Allen \& Meyer, 1990).

Meyer and Allen proposed a three component model of organizational commitment - affective, continuance, and normative commitment. Affective commitment is to have positive feelings about adopting, being attached to and identification with organizational goals. Employees with strong affective commitment continue to work in the organization because they want to do it (Allen \& Meyer, 1996; Bolon, 1997). Continuance commitment based on the costs that the employee will face in case of leaving from the institution and the costs he/she has to bear (Meyer et al., 2002). The employee feels compelled to stay in the organization and continues to work because of the concern that the cost of leaving from the institution will be high (Allen \& Meyer, 1990; Allen \& Meyer, 1996). Normative commitment refers to the values of the employee regarding the obligation to remain in the organization. It is a type of commitment that employees show since they consider commitment to organizational goals as a necessity with sense of moral obligation. Employees with high normative commitment continue to work, thinking that staying in the organization is right and ethical (Meyer \& Herscovitch, 2001).Two of the component developed on the basis of this model were first used in published research by Meyer and Allen in 1984 and the third, by Allen and Meyer in 1990 (Meyer at al., 2002).

The three components of commitment have different effects on job behavior. Continuance commitment was expected to develop in response to conditions (e.g., side bets) that increase the cost of leaving, whereas affective commitment was expected to be particularly sensitive to work experiences (e.g., job scope; organizational support). Normative commitment was believed to develop in response to social pressure. Hereby affective commitment was expected to have the strongest positive effect on desirable work behaviors (e.g., attendance, performance, organizational citizenship behavior), followed by normative commitment. Continuance commitment was expected to have little, or even a negative, impact on these behaviors (Powell \& Meyer, 2004; Allen \& Meyer, 1996; Meyer et al., 2002).

\section{TheEffect of Job Satisfaction on Organizational Commitment}

The importance of job satisfaction in terms of businesses stems from the potential results it contains. That is to say; workers who are in high morale shall be able to provide further benefits for the organization they work for. As happy workers, they will produce more, their days of absence in job will diminish and their commitment to the organization will increase (Gohel, 2009). Commitment to the organization, associated with staying, has a strong relationship with job satisfaction. However, rather than being antecedent, commitment is often placed causally after job satisfaction (Adams \& Bond, 2000).

Previous studies have shown that job satisfaction was directly related to organizational commitment and that it had a positive effect on organizational commitment (Yang \& Chang, 2008; Harrison \& Hubbard,1998; Bhuian \& Abul-Muhmin, 1997).Intrinsic and extrinsic job satisfaction was found to be a mediator between emotional intelligence and organizational commitment (Güleryüz et al., 2008).Markovits et al. (2010) reached the conclusion that extrinsic satisfaction and intrinsic satisfaction are more strongly related to affective commitment and normative commitment for public sector employees than for private sector ones. Jenkins and Thomlinson (1992) found positive association between affective commitment and job satisfaction, and negative association between continuance commitment and job satisfaction. The study applied to nurses by Knoop (1995) found that job satisfaction and organizational commitment of nurses are both statistically and meaningfully related.

Based on the above considerations, it could be hypothesized that:

Hla. Intrinsicsatisfaction directly and positively influences affective commitment.

H1b. Intrinsicsatisfaction directly and negatively influences continuancecommitment.

H1c. Intrinsic satisfaction directly and positively influences normative commitment.

H2a. Extrinsicsatisfaction directly and positively influences affective commitment.

H2b. Extrinsicsatisfaction directly and negatively influencescontinuance commitment.

H2c. Extrinsicsatisfaction directly and positively influencesnormative commitment.

The conceptual model that shows the hypothesized relationships among the variables is illustrated in Figure 1. 


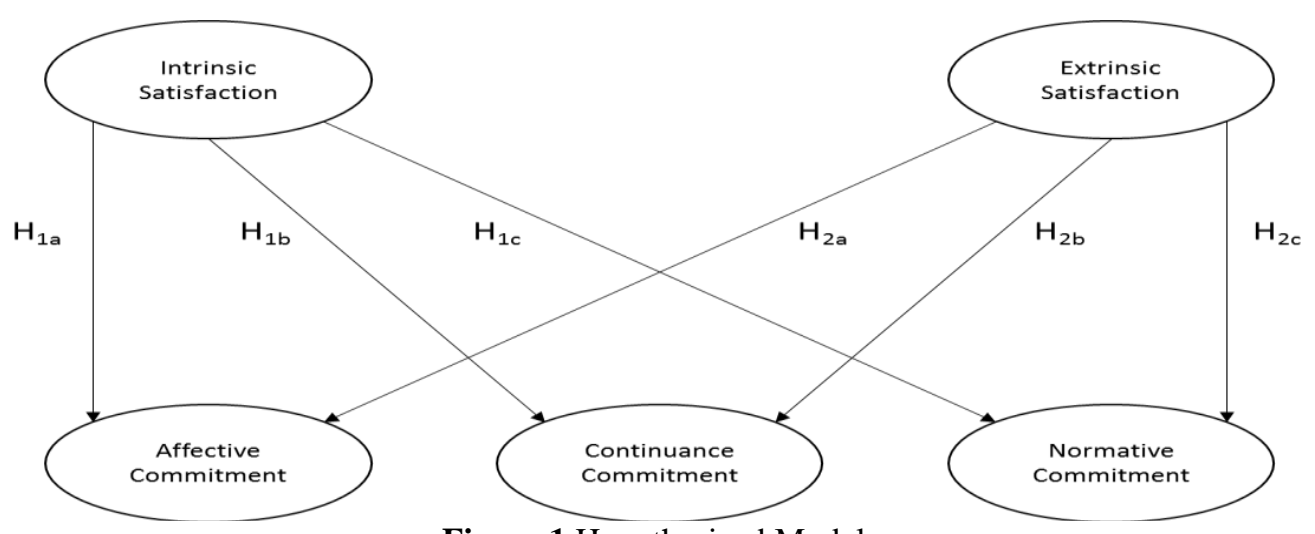

Figure 1.Hypothesized Model

\section{Population and Sample}

\section{Research Methodology}

The population of this research is made up of a total of 1671 people consisting of physicians (700), nurses (652), other health personnel (143) and administrative personnel (176) working for Akdeniz University Hospital that operates in the province of Antalya in Turkey. No sample was drawn in the research, the whole of the population was attempted to be covered and the data collection tool utilized in the research was distributed to all workers who agreed to participate in the research. The data collection period took place between JanuaryFebruary of 2014 and the answers of a total of 525 people were taken. During the computerization of survey responses, it was understood that 24 of the surveys could not be assessed and thus a total of 501 (30\%) usable surveys were attained.

When the distribution of the participants in the research is examined in terms of various demographic features, it is seen that $64.7 \%$ of them are women and $\% 35.3$ of them are men. $27.5 \%$ of the participants are physicians, $35.5 \%$ are nurses, $10.4 \%$ are other health personnel and $26.5 \%$ are administrative personnel. While $60 \%$ of the health personnel contributing to the research are aged 34 and below, $59.7 \%$ have a work experience of 9 years and below, which is the average term of employment. When viewed in terms of education, while $11.6 \%$ of the participants are high-school graduates, $29.9 \%$ hold associate, $38.5 \%$ hold bachelor and $20 \%$ hold master's degrees. A significant portion of the participants (61.3\%) are married.

\section{Data Collection Tools}

Minnesota Job Satisfaction Questionnaire, developed by Weis et al. (1967) was used to evaluate the job satisfaction of the participants. Minnesota Job Satisfaction Questionnaire respondents indicate how satisfied they are with various aspects of their present job. Minnesota Job Satisfaction Questionnaire has a long form (100 items) and a short form (20 items). In this study, the short form of the questionnaire, containing two dimensions: internal satisfaction and external satisfaction, is used. The questionnaire consisted of 20 questions on a 5-point Likert Scale.

In this study, in order to measure organizational commitment the Organizational Commitment Scale devised by Meyer, Allen and Smith (1993), which is widely utilized in literature, was used. In the scale consisting of a total of 18 questions, each dimension of commitment is assessed with 6 questions. However, in this study, organizational commitment is handled as a single dimension. For the items in the scale, a 5-point Likert-type scale ranging from strongly disagree (1) to strongly agree (5) was utilized.

\section{Data Analysis}

The reliability and validity of the measurement model was assessed by confirmatory factor analysis (CFA) using the SPSS Amos 23 software package. In addition, the fit for the hypothesized models was evaluated by using the following goodness of fit measures: the goodness of fit index (GFI); the adjusted goodness of fit index (AGFI); the normed fit index (NFI); the comparative fit index (CFI); and the root square mean of approximation (RMSEA). The next step in analyzing the data was to test the hypothesized models. In this case, this study conducted structural equation modeling (path analysis) using the SPSS Amos 23 software package.

\section{Research Results}




\section{Descriptive statistics}

The means, standard deviations, intercorrelations, and scale reliabilities among the key variables are presented in Table 1. According to the table, there is a positive and significant relationship between organizational commitment and job satisfaction.

Table 1. Descriptive statistics, reliabilities, and correlations among the variables

\begin{tabular}{|l|c|c|c|c|c|c|c|}
\hline \multicolumn{1}{|c|}{ Variables } & Mean & SD & 1 & 2 & 3 & 4 & 5 \\
\hline 1. Affective Commitment & 3.30 & .72 & 1 & & & & \\
\hline 2. Continuance Commitment & 2,57 & .81 & $-.093^{*}$ & 1 & & & \\
\hline 3. Normative Commitment & 3.26 & .75 & $.504^{* *}$ & $-.449^{* *}$ & 1 & & \\
\hline 4. Intrinsic Satisfaction & 3.59 & .69 & $.254^{* *}$ & $-.276^{* *}$ & $.485^{* *}$ & 1 & \\
\hline 5. Extrinsic Satisfaction & 3.28 & .81 & $.279^{* *}$ & $-.329^{* *}$ & $.561^{* *}$ & $.727^{* *}$ & 1 \\
\hline
\end{tabular}

Correlation is significant at the 0.05 level (2-tailed).

** Correlation is significant at the 0.01 level (2-tailed).

\section{Measurement model}

First, Confirmatory Factor Analysis(CFA) was conducted using the SPSS Amos 23 software package to test the variables. Then, the measurement model was tested, which included five latent factors (i.e., intrinsic satisfaction,extrinsic satisfaction, affective commitment continuance commitment, normativecommitment) and 38 indicators (18 items for organizational commitment, and 20 items for job satisfaction). The modification indices indicated that eleven variables should be dropped due to low factor loadings (six items from organizational commitment, and five items from job satisfaction). The goodness of fit indices is presented in Table 2.

Table 2.Goodness of fit indices

\begin{tabular}{lcccccccc}
\hline Model & $\boldsymbol{d} \boldsymbol{f}$ & $\boldsymbol{X}^{\mathbf{2}}$ & $\boldsymbol{X}^{\boldsymbol{2}} / \boldsymbol{d} \boldsymbol{f}$ & $\mathbf{G F I}$ & AGFI & NFI & CFI & RMSEA \\
\hline CFA model & 306 & 992.116 & 3.242 & 0.902 & 0.842 & 0.902 & 0.917 & 0.067 \\
Hypothesized model & 309 & 1052.711 & 3.407 & 0.887 & 0.835 & 0.889 & 0.900 & 0.069 \\
\hline
\end{tabular}

\section{Structural model}

Structural equation modeling (path analysis) was conducted using the Amos 23 software package to test the hypotheses. Having confirmed that the measurement model had adequate fit, the proposed structural model was tested. The results regarding the structural analysis of the proposed model provides an acceptable fit to the data (Arbuckle, 2010; Byrne, 2010) (see Table 2).

The first hypothesis examines the relationship between intrinsic satisfaction and affective commitment. No statistically significant influence of intrinsic satisfaction on affective organizational commitment was found $(\beta=-0.001, \mathrm{p}>0.05)$. The second hypothesis focuses on the relationship between intrinsic satisfaction and continuance commitment. In this case, no statistically significant influence of intrinsic satisfaction on continuance commitment was found $(\beta=0.29, \mathrm{p} \geq 0.05)$. The third hypothesis examines the effect of intrinsic satisfaction on normative commitment. The findings show that there was no statistically significant effect of intrinsic satisfaction on normative commitment $(\beta=-0.06, \mathrm{p}>0.05)$ (see Figure 2 ).

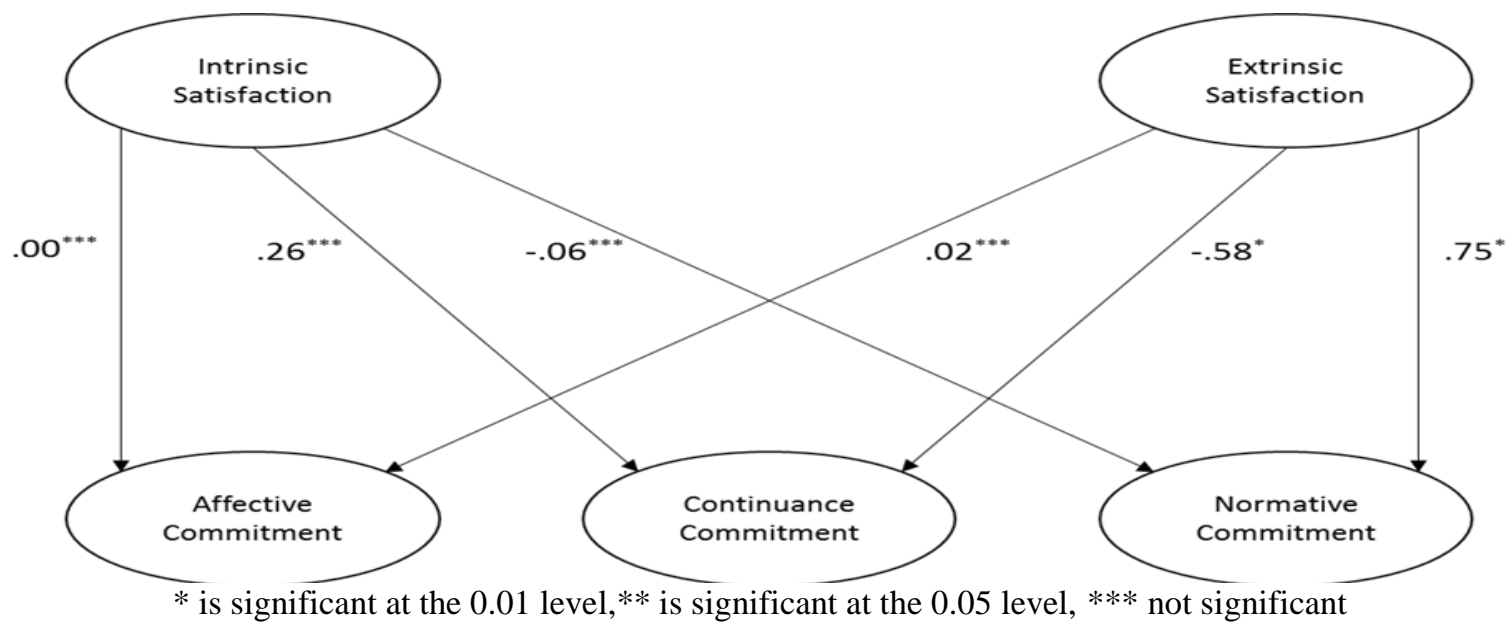

Figure 2.The Effect of Job Satisfaction on Organizational Commitment 
The fourth hypothesis measures the effect of extrinsic satisfaction on affective organizational commitment. In this regard, there was no statistically significant effect of extrinsic satisfaction on affective organizational commitment $(\beta=0.02, \mathrm{p}>0.05)$. The fifth hypothesis focuses on the effect of extrinsic satisfaction on continuance commitment. The results indicate that extrinsic satisfactionnegatively affects the continuance commitment of healthcare personnel $(\beta=-0.51, p<0.01)$, and an increase in the level of extrinsic satisfaction causes adecrease in continuance commitment. In support of Hypothesis 6 , the path coefficient between extrinsic satisfaction andnormative organizational commitment $(\beta=0.69, \mathrm{p}<0.01)$ was both positive and significant. The findings show that the extrinsic satisfaction of the healthcare personnel directly influences their normative commitment(see Figure 2).

The summary of the results are as follows:

H1a: Rejected $(\beta=-0.00, \mathrm{p}>0.05)$

H1b: Rejected $(\beta=0.29, \mathrm{p} \geq 0.05)$

H1c: Rejected $(\beta=-0.06, p>0.05)$

H2a: Rejected $(\beta=0.02, \mathrm{p}<0.05)$.

H2b: Accepted $(\beta=-0.51, p<0.01)$.

H2c: Accepted $(\beta=0.69, \mathrm{p}<0.01)$

\section{Discussion and Conclusion}

With the increase of technological advances and changes, there is a need for organizations to address employee satisfaction, organizational commitment and work itself. The success, survival and competing power of organizations depend on the commitment of their members, supporting their individual developments and ensure their participations. Some researches, examining the relationship between job satisfaction and organizational commitment showed that organizational commitment causes job satisfaction, but some researchessuggested that there was an interrelation between organizational commitment and job satisfaction. In this study, it was aimed to investigate the effect of job satisfaction on organizational commitment. As a result of the analyses, it was determined that there was no statistically significant influence of intrinsic satisfaction on organizational commitment; only extrintic satisfaction was found significantly negative effect on continuance commitment and positive effect on normative commitment. This means that extrintic factors like pay, promotion, supervision or working condition are more powerful for the healthcare personnel togenerate a commitment which is based on a feeling of obligation with the organization and a strongbelief about being a member of the organization is the right or moral thing to do, than internal factors like use of skills, job variety, experience.

The most important input of health institutions is the human factor. Even though there are structural, economic and physical conditions for organizational effectiveness, if the necessary attention are not given to healthcare professionals who are responsible for the presentation of the health services, and their needs and expectations are not met, their organizational commitment will be decreased due to job dissatisfaction; and this will affect the efficiency of the health institution and the health of the patients negatively. Whereas job satisfaction is more related to business environment, organizational commitment is related to reliance on management, management policies and relations with management. It is thought that providing job satisfaction of health workers will also affect the commitment to the institution positively. Job satisfaction is seen as an important goal and tool for health institutions in order to increase organizational commitment and keep employees in the institution. To keep employees in-house will be easier for the institutions which can increase and maintain the job satisfaction levels of employees than those which can't achieve it.

The employees working on the institutions which care about desire and needs of employees, are constantly in touch and have an exchange of ideas with them, will have more job satisfaction. High job satisfaction level will increase the organizational commitment level, particularly normative commitment level, and will make it easier to keep their successful employees in-house. Within the scope of strengthening normative commitment, managers should put excessive emphasis on applications for healthcare professionals. Inadequate and inaccurate applications are one of the reasons behind not showing organizational commitment by employees. Being fair in promotions, payments, awards and the selection of employees who will take further education, work safety and superior-subordinate relationship are important to develop normative commitment. It will be important to protect the qualified and hardworking employees and provide necessary rewards and satisfaction not to make them feel unhappy and underprivileged. 


\section{References}

[1] Adams,A. \& Bond, S. (2000). Hospital nurses' job satisfaction, individual and organizational characteristics, Journal of Advanced Nursing, 32(3), 536-543.

[2] Allen, N. \& Meyer, J. P. (1990). The Measurement and Antecedents of Affective, Continuance and Normative Commitment to the Organization, Journal of Occupational Psychology, Vol. 63: 1-18.

[3] Allen, N. J. \& Meyer, J. P. (1996). Affective, Continuance, and Normative Commitment to the Organization: An Examination of Construct Validity, Journal of Vocational Behavior, 49, 252-276, Article No. 0043.

[4] Arbuckle, J. L. (2010). IBM SPSS Amos 19 Users's Guide (Amos Development Corporation, Florida).

[5] Bhuian, S.N. \& Abdul-Muhmin, A.G. (1997). Job satisfaction and organizational commitmentamong 'guest-worker' salesforces: the case of Saudi Arabia, Journal of Global Marketing, Vol. 10 No. 3, pp. 27-44.

[6] Bolon, D. S. (1997). Organizational Citizenship Behavior Among Hospital Employees: A Multidimensional Analysis Involving Job Satisfaction and Organizational Commitment, Hospital \& Health Services Administration, Summer, 42, 2; ProQuest Business Collection, pp. 221-241.

[7] Byrne B. M. (2010). Structural Equation Modelling with AMOS: Basic Concepts, Applications, and Programming, Second Edition Taylor and Francis Group, New York.

[8] Currivan, D. B. (1999). The Causal Order of Job Satisfaction and Organizational Commitment in Models of Employee Turnover, Human Resource Management Review, Vol. 9, Num. 4, pp. 495-524.

[9] Gohel, K. (2009), "Psychological Capital as a Determinant of Employee Satisfaction", International Referred Research Journal, January, Vol. 3, ISSUE 36, 34-37.

[10] Güleryüz G., Güney S., Miski Aydın E. \& Aşan Ö. (2008). The mediating effect of job satisfaction between emotional intelligence and organisational commitment of nurses: A questionnaire survey, International Journal of Nursing Studies, 45: 1625-1635, doi: 10.1016/j.ijnurstu.2008.02.004

[11] Harrison, J.K. \&Hubbard, R. (1998). Antecedents to organizational commitment among Mexican employees of a US firm in Mexico, The journal of Social Psychology, Vol. 138(5), October, pp. 609-623.

[12] Jenkins, M. \& Thomlinson, R.P. (1992). Organizational commitment and job satisfaction aspredictors of employee turnover intentions, Management Research News, Vol. 15 No. 10, pp. 18-22.

[13] Knoop, R. (1995). Relationships Among Job Involvement, Job Satisfaction, and Organizational Commitment for Nurses, The Journal of Psychology, Volume 129, Issue 6.

[14] Lambert, E. G., Hogan, N. L. \& Griffin, M. L. (2007). The impact of distributive and procedural justice on correctional staff job stress, job satisfaction, and organizational commitment, Journal of Criminal Justice, 35: 644-656, doi: 10.1016/j.jcrimjus.2007.09.001.

[15] Larson, M. \& Luthans, F. (2006). Potential Added Value of Psychological Capital in Predicting Work Attitudes, Journal of Leadership \& Organizational Studies, 13: 45-62, DOI: 10.1177/10717919070130010701.

[16] Lu, H., While, A. E. \& Barriball, K. L. (2005). Job satisfaction among nurses: a literature review, International Journal of Nursing Studies, 42: 211-227, doi:10.1016/j.ijnurstu.2004.09.003.

[17] Markovits Y. , Davis A. J., Fay D. \& Van Dick R. (2010) The Link Between Job Satisfaction and Organizational Commitment: Differences Between Public and Private Sector Employees, International Public Management Journal, 13:2, 177-196, DOI: 10.1080/10967491003756682.

[18] Meyer J.P., Stanley D.J., Herscovitch L. \& Topolnytsky L. (2002). Affective, Continuance, and Normative Commitment to the Organization: A Meta-analysis of Antecedents, Correlates, and Consequences, Journal of Vocational Behavior, 61: 20-52, doi:10.1006/jvbe.2001.1842.

[19] Meyer, J.P. \& Allen, N.J., Smith, C.A. (1993). Commitment to Organizations and Occupations - Extension and Test of a 3 Component Conceptualization, Journal of Applied Psychology. 78(4): 538-551.

[20] Meyer, J.P. \& Herscovitch, L. (2001). Commitment in the workplace: Toward a general model, Human Resource Management Review, 11: $299-326$.

[21] Powell, D. M. \& Meyer, J. P. (2004). Side-bet theory and the three-component model of organizational commitment, Journal of Vocational Behavior, 65: 157-177, doi:10.1016/S0001-8791(03)00050-2.

[22] Shahnawaz, M. G. \& Jafri, Md. H. (2009). Psychological Capital as Predictors of Organizational Commitment and Organizational Citizenship Behaviour, Journal of the Indian Academy of Applied Psychology, Vol. 35, Special Issue, 78-84.

[23] Weiss, H. M. (2002). Deconstructing Job Satisfaction Separating Evaluations, Beliefs and Affective Experiences, Human Resource Management Review, 12: 173 - 194

[24] Yang, F.H. \& Chang, C.C. (2008). Emotional labour, job satisfaction and organizational commitment amongst clinical nurses: A questionnaire survey, International Journal of Nursing Studies, 45: 879-887, doi. 10.1016/j.ijnurstu.2007.02.001. 